\title{
Response to Selection for Salt Tolerance during Germination in Tomato Seed Derived from PI 174263
}

\author{
M.R. Foolad ${ }^{1}$ \\ Department of Horticulture, The Pennsylvania University, 103 Tyson Building, Univerisity Park, \\ PA 16802
}

Additional index words. Lycopersicon esculentum, heritability, genetic correlation, breeding

\begin{abstract}
The effectiveness of directional phenotypic selection to improve tomato (Lycopersicon esculentum Mill.) seed germination under salt-stress was investigated. Seed of $F_{2}$ and $F_{3}$ progeny of $F_{1}$ hybrids between a salt-tolerant (PI174263) and a salt-sensitive (UCT5) tomato cultivar were evaluated for germination response at three stress levels of 100 (low), 150 (intermediate), and $200 \mathrm{~mm}$ (high) synthetic sea salt (SSS). At each salt-stress level, the most tolerant individuals, as determined by the germination speed, were selected. Selected individuals $\left(F_{2} s\right.$ or $\left.F_{3} s\right)$ were grown to maturity and selfpollinated to produce $F_{3}$ and $F_{4}$ progeny families. The selected progeny from each experiment were evaluated for germination at four treatment levels of 0 (nonstress), 100, 150, and $200 \mathrm{~mm}$ SSS and were compared with unselected populations. The results indicated that selections were equally effective at all three salt-stress levels and in $F_{2}$ and $F_{3}$ generations and significantly improved seed germination of progeny under salt-stress and nonstress treatments. Estimates of realized heritability for rapid germination under the various salt-stress levels ranged from 0.67 to 0.76 . Analysis of response and correlated response to selection indicated a genetic correspondence of up to $100 \%$ between germination at different salt-stress levels. Genotypic family correlations between germination at the low, intermediate, and high saltstress levels ranged from 0.67 to 0.89 , and those between nonstress and salt-stress conditions ranged from 0.25 (between 0 and $200 \mathrm{~mm}$ ) to 0.71 (between 0 and $100 \mathrm{~mm}$ salt). The results indicated that similar or identical genes with additive genetic effects contributed to rapid germination response of tomato seeds at different salt-stress levels. Thus, selection at one stress level resulted in progeny with improved germination at diverse salt-stress levels. The results also indicated that to improve tomato seed germination, selection can be based on individual seed performance and early segregating generations.
\end{abstract}

Salinity stress is a major environmental constraint to irrigated agriculture in the arid and semi-arid regions of the world. It is estimated that between $30 \%$ and $40 \%$ of the world's irrigated agricultural lands are afflicted by accumulated salts (Flowers et al., 1986). This estimate fails to account for the additional lands that are not considered to be arable due to high concentrations of salts and could possibly be brought into cultivation if more salt tolerant species or cultivars were available. Cultural practices, including implementation of large engineering schemes for reclamation, drainage, and irrigation with high-quality water, although essential, are usually expensive and often provide only a temporary solution to the problem. A complementary and more permanent approach to minimizing deleterious effects of soil and water salinity is to develop cultivars that can grow and produce economically sufficient yields under saline conditions (Epstein et al., 1980).

Development of a breeding program to improve crop salt tolerance requires knowledge of inheritance of tolerance-related traits and efficient selection criteria. Considerable information is available regarding physiological aspects of plant responses to salt (e.g., Gorham et al., 1985; Greenway and Munns, 1980; Lauchli and Epstein, 1990); however, information about genetic control of salt tolerance is limited. Insufficient genetic knowledge has se-

Received for publication 14 Feb. 1996. Accepted for publication 18 June 1996. I thank Richard Craig, Paul Grun, Douglas Shaw, and Michael Uchneat for critical reading of the manuscript and providing useful comments and suggestions. Financial support from the California Tomato Board and College of Agricultura Sciences at The Pennsylvania State Univ. is appreciated. The cost of publishing this paper was defrayed in part by the payment of page charges. Under postal regulations, this paper therefore must be hereby marked advertisement solely to indicate this fact.

${ }^{1}$ Assistant professor of plant genetics. verely restricted breeding efforts (Foolad and Jones, 1991, 1992a; Johnson et al., 1992; Tal, 1985).

Plant salt tolerance is a developmentally regulated stage-specific phenomenon. Tolerance at one stage of plant development is poorly correlated with tolerance at other developmental stages (e.g., Greenway and Munns, 1980; Johnson et al., 1992; Shannon, 1985). Specific stages throughout ontogeny of the plant, such as seed germination and emergence, seedling survival and growth, vegetative growth, and reproduction, should be evaluated separately for assessing tolerance and identifying useful genetic material. Such analyses may simplify underlying genetic components and therein facilitate breeding efforts aimed at introgressing tolerance components into superior breeding lines. In addition, the identified genetic components may be amenable to molecular techniques of gene transfer.

In most saline soils, salt concentrations vary substantially from location to location and from season to season (Richards, 1983). Breeders would like to develop cultivars that perform well under diverse salt-stress levels. Limited information is available regarding the relationships for plant tolerance among different salt-stress levels and for plant performance under stress and nonstress conditions. Different genetic and physiological mechanisms may be responsible for tolerance responses at different salt-stress levels (Jones and Qualset, 1984). Studies of inheritance of salt tolerance and estimation of genetic correlations among tolerances at different stress levels may provide information on similarity of genetic mechanism(s) contributing to tolerance under different stress levels. Such information also could be useful to breeders in developing appropriate selection and breeding strategies.

In many crop species, including tomato seed germination and early seedling growth are the most sensitive developmental stages to salinity stress (Ayers and Hayward, 1948; Cook, 1979; Jones, 
1986; Maas, 1986). Salinity stress greatly delays onset, reduces the rate, and increases the dispersion of germination events. Dependence on mechanization in modern plant cultivation systems requires rapid, uniform, and complete germination. Development of tomato cultivars with the ability to germinate rapidly and emerge reliably from saline-affected soils would contribute significantly to efficiency of stand establishment. Within Lycopersicon, potential sources of salt tolerance have been identified among wild species as well as cultivated tomato (e.g., Jones 1986; Rush and Epstein 1976; Tal and Shannon, 1983). The usefulness of such variation in crop improvement programs, however, has not been evaluated critically. This study investigated the effectiveness of directional phenotypic selection to improve tomato seed germination under different salt-stress levels. Phenotypic, genotypic, and genetic correlations among germination responses at different salt-stress levels and relationships between germination under salt-stress and nonstress conditions were determined.

\section{Materials and Methods}

Plant material. Highly inbred sources of PI174263, a primitive cultivar from arid lands in Turkey, and UCT5, a horticulturally superior, multiple-disease-resistant advanced breeding line, were crossed to generate $\mathrm{F}_{1}$ progeny. The former accession germinates rapidly under high salinity while the latter is highly sensitive to salt stress at all stages of plant development, including germination (Foolad 1996; Foolad and Jones 1991, 1992a; Jones, 1986). To prevent any confounding cytoplasmic effects on germination performance of progeny, all crosses were made with UCT5 as the female parent (Foolad and Jones, 1992b). The $\mathrm{F}_{2}$ generation was produced by controlled selfing of $F_{1}$ plants under greenhouse conditions. The $\mathrm{F}_{3}$ generation similarly was obtained by selfpollinating and bulk-harvesting seed from $200 \mathrm{~F}_{2}$ plants.

Germination and selection conditions. Sterile germinating media (0.8\% agar) containing 0 (control), 100 (low), 150 (medium), and $200 \mathrm{~mm}$ (high) synthetic sea salt (SSS; Rila-Mix, Trenton, N.J.; adjusted to a $\mathrm{Na}^{+}: \mathrm{Ca}^{2+}$ molar ratio equal to 5) were prepared in petri dishes. The water potentials of treatment media were-0.10,
$-0.60,-0.80$, and $-1.06 \mathrm{MPa}$, respectively, as measured on a vapor pressure osmometer (model 5100; Wescor, Logan, Utah). Seed of parents and $\mathrm{F}_{2}$ and $\mathrm{F}_{3}$ generations were surface-sterilized with $0.5 \%$ sodium hypochlorite solution for $10 \mathrm{~min}$; rinsed with sterile, distilled water several times; and briefly blotted. For each salt concentration, 500 seeds each of the $\mathrm{F}_{2}$ and $\mathrm{F}_{3}$ generations and 300 seeds each of the parental inbred lines were sown on germination media under aseptic conditions. Each petri dish contained 100 seeds. Seed of the $\mathrm{F}_{3}$ generation were sown only at the 0 and 200 mM salt concentrations. Petri dishes were randomized in an incubator maintained in darkness at $20 \pm 0.5^{\circ} \mathrm{C}$. Germination response was scored visually as radicle protrusion at $6-\mathrm{h}$ intervals for the first $15 \mathrm{~d}, 12-\mathrm{h}$ intervals for the next $20 \mathrm{~d}$, and at daily intervals for an additional $25 \mathrm{~d}$. Seed lot viability was determined to be $96 \%$ (i.e., $\approx 480$ seeds germinated from a total 500 in each generation).

In each $\mathrm{F}_{2}$ or $\mathrm{F}_{3}$ population, the 35 fastest germinating seeds (7.3\% of a total of 480 viable seeds) were selected as the salttolerant individuals. Assuming a normal phenotypic distribution for seed germination, this proportion of selection corresponds to a selection intensity of $i=1.899$ (Falconer, 1981). In the $\mathrm{F}_{2}$ generation, selection was made at 100-, 150-, and 200-mm salt-stress levels, whereas in the $\mathrm{F}_{3}$ generation selection was made only at 200 mM. Thus, there were four selection experiments (Fig. 1). Selected seedlings were transferred from petri dishes into plastic pots and subsequently into the field where they were grown to maturity. Plants were self-pollinated, and progeny seeds were collected from individual plants.

Progeny evaluation. The $35 \mathrm{~F}_{3}$ or $\mathrm{F}_{4}$ families from each of the four selection experiments were evaluated for germination response at four salt concentrations of 0, 100, 150, and $200 \mathrm{~mm}$ SSS (Fig. 1). At each salt concentration, 300 seeds of each family were included in three petri dishes (equivalent to three replications). In addition, in all experiments, 300 seeds of each of the parental inbred lines (UCT5 and PI174263) and 500 seeds of each of the unselected $\mathrm{F}_{2}$ and $\mathrm{F}_{3}$ populations were included as controls. Seed of the unselected $\mathrm{F}_{4}$ population were included only in the last experiment when selected $\mathrm{F}_{4}$ families were being evaluated for germination. Because progeny evaluations for each of the four selection

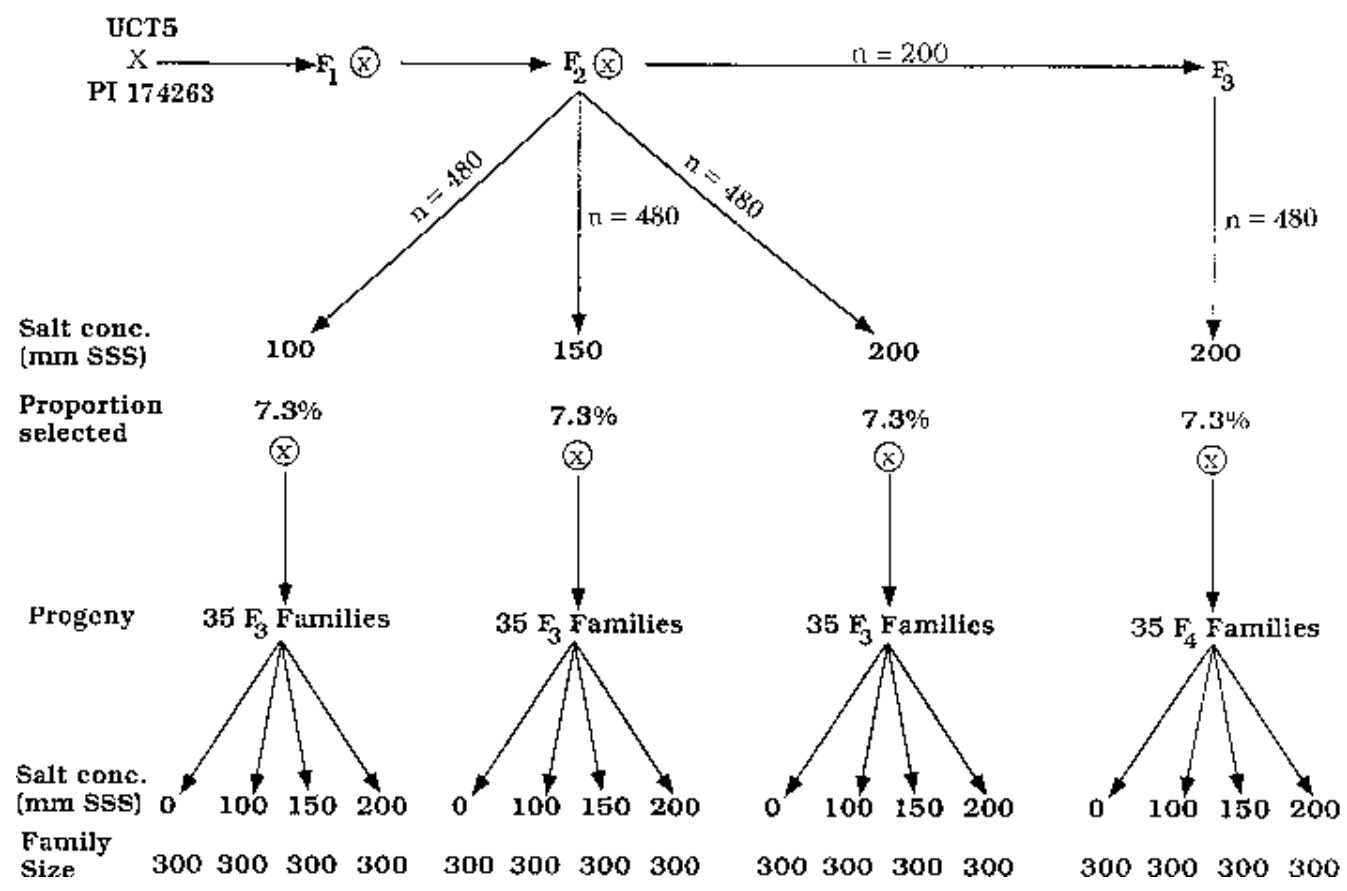

Fig. 1. Schematic representation of the experiments conducted to measure response to selection for salt tolerance during germination in tomato and to estimate realized heritabilities and genetic correlations under different salt-stress levels. 
experiments were conducted at different times (equivalent to different years), germination of the parental inbred lines and unselected populations were used as controls to determine possible differences between times of progeny evaluation.

Estimation of means and variances. Germination distributions of parental inbred lines, and unselected and selected populations were analyzed by survival analysis with life tables (Gehan, 1969; Lee, 1980; Scott and Jones, 1982), and the time to 50\% germination (T50) was determined. T50 was used as an estimate of the population germination mean. Means and variances were determined for samples within each replicate (petri dish) and were pooled over replicates. In parent and progeny generations, seeds that failed to germinate in the control treatment ( $0 \mathrm{~mm}$ salt) were presumed to have been nonviable initially. Above this control percentage, seeds that failed to germinate in the salt treatment were included in the analysis as right-censored observations (Gehan, 1969; Scott and Jones, 1982). Hence, sample size for each experimental unit was the number of viable seeds, not the number observed to germinate.

Estimation of heritabilities. Heritabilities of seed germination under various salt-stress levels were estimated by two methods. The first method estimated broad sense heritability $\left(\mathrm{H}_{\mathrm{B}}\right)$ using components of variances in unselected $\mathrm{F}_{2}, \mathrm{~F}_{3}$, and $\mathrm{F}_{4}$ populations [e.g., $\mathrm{H}_{\mathrm{B}(\mathrm{F} 2)}=\left(\mathrm{V}_{\mathrm{F} 2}-\mathrm{V}_{\mathrm{E}}\right) \div \mathrm{V}_{\mathrm{F} 2}$ ] (Falconer, 1981; Hanson, 1963; Mather and Jinks, 1971). Environmental variance $\left(V_{E}\right)$ at each salt concentration was estimated as the average of the germination variances of the two parental inbred lines. SE of the heritability estimates were calculated using the formula provided by Ginkel and Scharen (1987). The second method estimates realized heritability $\left(\mathrm{H}_{\mathrm{R}}\right)$ using the formula $\mathrm{H}_{\mathrm{R}}=\mathrm{R} \div \mathrm{D}$ (Falconer, 1981). Selection differential (D) was measured as the difference between the germination mean of the selected individuals $\left(\mathrm{F}_{2}\right.$ or $\left.\mathrm{F}_{3}\right)$ and that of the population before selection $\left(\mathrm{F}_{2}\right.$ or $\left.\mathrm{F}_{3}\right)$. Selection response $(\mathrm{R})$ was measured as the difference between the germination mean of the selected progeny $\left(\mathrm{F}_{3}\right.$ or $\left.\mathrm{F}_{4}\right)$ and that of an unselected population $\left(\mathrm{F}_{3}\right.$ or $\left.\mathrm{F}_{4}\right)$ grown at the same time and conditions. To reduce the scaling effects of differing environments (different years) on heritability estimates, realized heritabilities were computed based on standard-unit data (Frey and Horner, 1957).

Estimation of correlations. Phenotypic $\left(\mathrm{r}_{\mathrm{p}}\right)$ and genotypic $\left(\mathrm{r}_{\mathrm{G}}\right)$ family correlations between germination at different salt-stress levels were estimated in all four selection experiments using the $\mathrm{F}_{3}$ or $\mathrm{F}_{4}$ progeny data (Falconer, 1981). Because the estimates were similar across experiments, data were pooled and correlation coefficients were re-estimated using $\approx 120$ family means for each pairwise comparison. Phenotypic correlations were estimated based on total phenotypic variances and covariances among families, whereas genotypic correlations were based on total genetic (i.e., additive plus non-additive) variances and covariances (Falconer, 1981). The significance of phenotypic correlations was determined using the table of correlation coefficients (Steel and Torrie, 1980). The significance of genotypic correlations was inferred from the significance level of phenotypic correlations.

By considering seed germination at different salt-stress levels as separate traits, response to selection (e.g., selection and progeny evaluation at the same treatment level) and correlated response to selection (e.g., selection at $100 \mathrm{~mm}$ and progeny evaluation at 150 mM salt-stress treatment) were measured in different selection experiments. The genetic correlations $\left(\mathrm{r}_{\mathrm{A}}\right)$ then were estimated following Falconer (1981): $r_{A}=\left(C_{X} C_{Y} / R_{X} R_{Y}\right)^{1 / 2}$, where, $C_{X}$ is the correlated response at the salt concentration of $\mathrm{X}$ due to selection at the salt concentration of $\mathrm{Y}$, and $\mathrm{R}_{\mathrm{X}}$ is the selection response (selection gain) at the salt concentration of $\mathrm{X}$ due to selection at the same salt concentration, X. Theoretically genetic correlations are less biased by non-additive genetic effects compared to phenotypic and genotypic correlations (Falconer, 1981). The significance of $\mathrm{r}_{\mathrm{A}}$ could not be determined because no adequate statistical test was available.

The pairwise correlations between the time to $25 \%, 50 \%$, and $75 \%$ germination were estimated using the $\mathrm{F}_{3}$ and $\mathrm{F}_{4}$ progeny data.

\section{Results}

Germination performance of parental lines and unselected populations. Seed of PI174263 germinated significantly faster than seed of UCT5 under control (no salt) and salt-stress treat-

Table 1. Days to $50 \%$ germination $( \pm \mathrm{SE})$ of the parental tomato inbred lines and unselected segregating populations at four salt-stress levels. ${ }^{\mathrm{z}}$

\begin{tabular}{lcccc}
\hline & \multicolumn{4}{c}{ Salt level (mM) } \\
\cline { 2 - 5 } Generation & 0 & 100 & 150 & 200 \\
\hline PI174263 & $1.81 \pm 0.04$ & $3.84 \pm 0.19$ & $7.29 \pm 0.61$ & $18.67 \pm 1.28$ \\
UCT5 & $2.70 \pm 0.06$ & $7.13 \pm 0.14$ & $22.50 \pm 2.00$ & $>60^{y}$ \\
$F_{2}$ & $2.40 \pm 0.05$ & $6.55 \pm 0.17$ & $13.89 \pm 0.50$ & $55.31 \pm 1.56$ \\
$F_{3}$ & $2.56 \pm 0.07$ & $6.40 \pm 0.20$ & $14.34 \pm 1.06$ & $53.19 \pm 1.87$ \\
$F_{4}$ & $2.74 \pm 0.05$ & $6.58 \pm 0.17$ & $15.40 \pm 1.85$ & NA $^{\mathrm{x}}$
\end{tabular}

${ }^{\mathrm{z}}$ Each value is a mean estimate averaged over two to five experiments $\pm \mathrm{SD}$ among experiments. Seed were germinated in darkness on media in petri dishes at $20 \pm 0.5^{\circ} \mathrm{C}$.

yDid not reach $50 \%$ germination at $60 \mathrm{~d}$.

${ }^{x}$ Not available.

Table 2. Germination variance of the parental tomato inbred lines and unselected segregating populations at three salt-stress levels. ${ }^{z}$

\begin{tabular}{lccr}
\hline & \multicolumn{3}{c}{ Salt level $(\mathrm{mM})$} \\
\cline { 2 - 4 } Generation & 0 & 100 & \multicolumn{1}{c}{150} \\
\hline PI174263 & $0.116 \pm 0.012$ & $1.073 \pm 0.114$ & $3.782 \pm 0.508$ \\
UCT5 & $0.123 \pm 0.010$ & $0.898 \pm 0.095$ & $6.209 \pm 0.782$ \\
$\mathrm{~F}_{2}$ & $0.175 \pm 0.014$ & $2.740 \pm 0.230$ & $13.980 \pm 2.130$ \\
$\mathrm{~F}_{3}$ & $0.265 \pm 0.014$ & $3.088 \pm 0.193$ & $17.030 \pm 2.237$ \\
$\mathrm{~F}_{4}$ & $0.298 \pm 0.017$ & $3.948 \pm 0.218$ & $16.932 \pm 2.183$
\end{tabular}

${ }^{\mathrm{z}}$ Each value is a mean estimate averaged over two to five experiments $\pm \mathrm{SD}$ among experiments. Seed were germinated in darkness on media in petri dishes at $20 \pm 0.5^{\circ} \mathrm{C}$.

Table 3. Selection response (percent) for rapid germination of tomato seed at different salt-stress levels and in different generations. ${ }^{\mathrm{z}}$

\begin{tabular}{|c|c|c|c|c|c|}
\hline \multicolumn{2}{|c|}{ Selection } & \multicolumn{4}{|c|}{$\begin{array}{l}\text { Salt-stress level during } \\
\text { progeny evaluation (mM) }\end{array}$} \\
\hline Salt level & Generation & 0 & 100 & 150 & $200^{y}$ \\
\hline$\overline{100}$ & $\mathrm{~F}_{2}$ & $7.8^{*}$ & $28.4^{* * *}$ & $45.5^{* * *}$ & 57.3 \\
\hline 150 & $\mathrm{~F}_{2}^{2}$ & $8.3^{*}$ & $24.9^{* *}$ & $45.4^{* *}$ & 53.0 \\
\hline 200 & $\mathrm{~F}_{2}^{2}$ & $14.3^{* *}$ & $23.6^{* *}$ & $46.2^{\text {** }}$ & 56.7 \\
\hline 200 & $\mathrm{~F}_{3}^{2}$ & $12.0^{* * *}$ & $24.0^{* * *}$ & $49.7^{* * *}$ & 70.3 \\
\hline
\end{tabular}

${ }^{\mathrm{z}}$ Selection response was calculated as the difference in germination mean between selected and unselected populations and transformed into percentage relative to germination mean of unselected populations. Seed were germinated in darkness on media in petri dishes at $20 \pm 0.5^{\circ} \mathrm{C}$.

${ }^{\mathrm{y}}$ Significance of selection response could not be determined because no adequate estimate of germination variance was obtained at 200-mm salt treatment.

${ }^{* * * *}$ Significant at $P \leq 0.05$ and 0.01 , respectively. 
ments. The difference between the two, however, was greater in the presence of salt and increased with increasing salt concentration (Table 1). At the highest salt concentration (200 mM), UCT5 did not reach $50 \%$ germination by the end of experiments $(60 \mathrm{~d})$. Seed of unselected $\mathrm{F}_{2}, \mathrm{~F}_{3}$, and $\mathrm{F}_{4}$ populations germinated similarly to each other at all treatments. However, under nonstress treatment, their germination responses were similar to the salt-sensitive parent, whereas under salt-stress treatments they were intermediate between the two parents (Table 1). For each of the parental or unselected segregating generations, there was no significant differences among different experiments (data not shown).

The parental and unselected populations exhibited larger germination variances under stress than nonstress treatments, and variances increased with increasing salt concentration (Table 2). The segregating populations exhibited larger germination variances than the parental lines under stress and nonstress treatments (Table 2). Because many seeds did not germinate at $200 \mathrm{~mm}$ salt, an adequate estimate of variance was not obtained at this salt-stress treatment.

Effect of selection on germination of progeny seed. In either $\mathrm{F}_{2}$ or $\mathrm{F}_{3}$ generations, selection for rapid germination under salt-stress significantly improved germination performance of progeny. At each salt concentration, selection response (genetic gain) was measured as the difference in germination mean between the selected progeny and an unselected population of the same generation evaluated at the same time and conditions (except for the selected $\mathrm{F}_{4}$ progeny for which the mean was compared with the mean of an unselected $\mathrm{F}_{3}$ population). To express the results in a

Table 4. Estimates of broad sense and realized heritability $( \pm \mathrm{SE})$ for tomato seed germination at different salt-stress levels. ${ }^{\mathrm{z}}$

\begin{tabular}{lcccc}
\hline & \multicolumn{4}{c}{ Salt level $(\mathrm{mM})$} \\
\cline { 2 - 5 } Heritability $^{\mathrm{y}}$ & 0 & 100 & 150 & 200 \\
\hline $\mathrm{H}_{\mathrm{B}}\left(\mathrm{F}_{2}\right)$ & $0.32 \pm 0.03^{\mathrm{x}}$ & $0.64 \pm 0.03$ & $0.64 \pm 0.05$ & $\mathrm{NA}^{\mathrm{w}}$ \\
$\mathrm{H}_{\mathrm{B}}\left(\mathrm{F}_{3}\right)$ & $0.55 \pm 0.06$ & $0.68 \pm 0.04$ & $0.71 \pm 0.02$ & $\mathrm{NA}$ \\
$\mathrm{H}_{\mathrm{B}}\left(\mathrm{F}_{4}\right)$ & $0.60 \pm 0.05$ & $0.75 \pm 0.05$ & $0.70 \pm 0.04$ & $\mathrm{NA}$ \\
$\mathrm{H}_{\mathrm{R}}\left(\mathrm{F}_{2} / \mathrm{F}_{3}\right)$ & & 0.67 & 0.73 & 0.74 \\
$\mathrm{H}_{\mathrm{R}}\left(\mathrm{F}_{3} / \mathrm{F}_{4}\right)$ & & & & 0.76 \\
\hline
\end{tabular}

${ }^{\mathrm{z}}$ Seed were germinated in darkness on media in petri dishes at $20 \pm 0.5^{\circ} \mathrm{C}$. ${ }^{\mathrm{y}} \mathrm{H}_{\mathrm{B}}\left(\mathrm{F}_{2}\right)$, broad sense heritability estimated in $\mathrm{F}_{2}$ generation; $\mathrm{H}_{\mathrm{R}}\left(\mathrm{F}_{2} / \mathrm{F}_{3}\right)$, realized heritability estimated based on $\mathrm{F}_{2} / \mathrm{F}_{3}$ generations.

${ }^{x}$ Each value is a mean estimate averaged over two to five experiments. ${ }^{w}$ Not available.

Table 5. Estimates of phenotypic $\left(\mathrm{r}_{\mathrm{P}}\right)$, genotypic $\left(\mathrm{r}_{\mathrm{G}}\right)$, and genetic $\left(\mathrm{r}_{\mathrm{A}}\right)$ correlations between germination responses of tomato seed at four salt-stress levels. ${ }^{\mathrm{z}}$

\begin{tabular}{lcccc}
\hline \hline Salt & & \multicolumn{3}{c}{ Salt level $(\mathrm{mM})$} \\
\cline { 3 - 5 } level $(\mathrm{mM})$ & Correlation & 100 & 150 & 200 \\
\hline 0 & $\mathrm{r}_{\mathrm{P}}$ & $0.69^{* *}$ & $0.45^{* *}$ & $0.24^{*}$ \\
& $\mathrm{r}_{\mathrm{G}}$ & $0.71^{* *}$ & $0.47^{* *}$ & $0.25^{*}$ \\
100 & $\mathrm{r}_{\mathrm{P}}$ & & $0.87^{* *}$ & $0.66^{* *}$ \\
& $\mathrm{r}_{\mathrm{G}}$ & & $0.89^{* *}$ & $0.67^{* *}$ \\
& $\mathrm{r}_{\mathrm{A}}$ & & 0.92 & 0.93 \\
150 & $\mathrm{r}_{\mathrm{P}}$ & & & $0.84^{* *}$ \\
& $\mathrm{r}_{\mathrm{G}}$ & & & $0.86^{* *}$ \\
& $\mathrm{r}_{\mathrm{A}}$ & & & 1.00
\end{tabular}

${ }^{\mathrm{z}}$ Seed were germinated in darkness on media in petri dishes at $20 \pm 0.5^{\circ} \mathrm{C}$.

${ }^{*}, * *$ Significant at $P \leq 0.05$ and 0.01 , respectively. more comparative way across selection experiments, selection response was calculated as percent response (Table 3). Statistical significance of selection response was determined by a $t$ test (Steel and Torrie, 1980). Due to the lack of adequate estimates of variance at the $200 \mathrm{~mm}$ treatment, significance of response at this salt-stress level could not be determined. The results indicated that selections at all three salt-stress levels (100, 150, and $200 \mathrm{~mm} \mathrm{SSS})$, and in $\mathrm{F}_{2}$ and $\mathrm{F}_{3}$ generation were equally effective in improving germination response of progeny under salt-stress treatments (Table 3). In addition, selection for rapid germination under saltstress significantly improved germination of progeny under nonstress treatment (Table 3).

Heritabilities. Broad-sense heritability $\left(\mathrm{H}_{\mathrm{B}}\right)$ estimates for germination under salt-stress treatments were similar across $\mathrm{F}_{2}, \mathrm{~F}_{3}$, and $\mathrm{F}_{4}$ generations and ranged from 0.64 to 0.75 . Heritabilities under nonstress treatment were smaller and ranged from 0.32 to 0.60 (Table 4). Realized heritabilities $\left(H_{R}\right)$ under salt-stress treatments were similar to broad-sense heritabilities, ranging from 0.67 to 0.76 , and were comparable across generations $\left(\mathrm{F}_{2} / \mathrm{F}_{3}\right.$ and $\left.\mathrm{F}_{3} / \mathrm{F}_{4}\right)$ and salt concentrations (100, 150, and $200 \mathrm{~mm}$ ) (Table 4).

Correlations. There were highly significant correlations between germination responses at different salt-stress levels. For example, genotypic correlation coefficients $\left(r_{G}\right)$ ranged from 0.67 (between 100 and $200 \mathrm{~mm}$ salt-stress treatments; $P \leq 0.01$ ) to 0.89 (between 100 and $150 \mathrm{~mm}$ salt concentrations; $P \leq 0.01$ ) (Table 5). There also were significant but smaller correlations between germination response under stress and nonstress treatments. For example, genotypic correlation coefficients ranged from 0.25 (between 0 and $200 \mathrm{~mm}$ salt-stress treatments; $P \leq 0.05$ ) to 0.71 (between 0 and $100 \mathrm{~mm}$ salt salt-stress treatments; $P \leq 0.01$ ) (Table 5). Phenotypic correlations $\left(\mathrm{r}_{\mathrm{p}}\right)$ were similar to genotypic correlations (Table 5). Genetic correlations $\left(\mathrm{r}_{\mathrm{A}}\right)$, estimated based on the response correlated-response equation (see materials and methods section), were large, ranging from 0.92 (between 100 and $150 \mathrm{~mm}$ ) to 1.00 (between 150 and $200 \mathrm{~mm}$ salt salt-stress treatments) (Table $5)$.

Correlation analyses indicated that in all experiments, the time to $25 \%$ (T25), 50\% (T50), and 75\% (T75) germinations were highly correlated with each other (Table 6). However, correlation coefficients between T25 and T50, and T50 and T75 were greater than those between T25 and T75.

\section{Discussion}

Slower seed germination under salt-stress compared to nonstress treatments could be due to osmotic or ionic effects of the saline germination media. Physiological studies to critically distinguish between the two are limited (Bliss et al., 1986). However, accumulating evidence suggest that low water potential of the germination media is a major limiting factor (Bradford, 1990, 1995; Haigh and Barlow, 1987). In the context of this discussion, the term "salt tolerance during germination" is used only to imply situations where seed has the ability to germinate rapidly under salt-stress conditions. No distinction is made between osmotic and ionic effects of the germination media. For a detailed discussion of seedwater relations during germination, refer to the recent review by Bradford (1995) and the references therein.

Previously, we estimated the heritability of salt tolerance during germination in tomato to be moderately high based on both variance component analysis $\left(\mathrm{H}_{\mathrm{N}}=0.74 \pm 0.03\right)$ (Foolad and Jones, 1991) and parent-offspring regression $\left[\mathrm{H}_{(\mathrm{F} 2: 3)}=0.76 \pm 0.05, \mathrm{H}_{(\mathrm{F} 3: 4)}\right.$ $=0.73 \pm 0.06]$ (Foolad and Jones 1992a). In this study, selection for rapid germination under salt-stress significantly improved germi- 
nation performance of progeny seed, and the realized gains were comparable to expected gains based on previous heritability estimates (data not shown). These results indicate contribution of nuclear genes with strong additive effects on this seed trait in tomato. Because parents and progeny were evaluated at different times (different environments), the realized gains and, thus, the realized heritability estimates would not be biased by genotype $\times$ environment interactions (Casler, 1982) and minimally inflated by environmental correlations among parent and progeny (Vogel et al., 1980). Any confounding effect of cytoplasm on germination performance was eliminated by using UCT5 as the maternal parent in all crosses (Foolad and Jones, 1992b). The involvement of mainly additive genetic components in germination performance under salt-stress should facilitate selection efforts for improving salt tolerance in breeding programs.

Selections were equally effective in $\mathrm{F}_{2}$ and $\mathrm{F}_{3}$ generations, suggesting absence of significant dominance genetic effects. If dominance were significant for rapid germination, smaller genetic gain would be expected from selection in $\mathrm{F}_{2}$ than in $\mathrm{F}_{3}$ generation. This is because of greater heterozygosity and, thus, greater expression of dominance effects, if present, in $\mathrm{F}_{2}$ than in $\mathrm{F}_{3}$ generation (Falconer, 1981; Mather and Jinks, 1971). In addition, under all three stress levels, the unselected $\mathrm{F}_{2}, \mathrm{~F}_{3}$, and $\mathrm{F}_{4}$ populations exhibited germination responses similarly to each other and intermediate between the two parents, which further indicates absence of significant dominance genetic effects for this seed trait in tomato. These results are consistent with our previous conclusions from a generation means analysis (Foolad and Jones, 1991) and a parent-offspring regression analysis of salt tolerance during germination in tomato (Foolad and Jones, 1992a). The combined results strongly indicate that tomato seed germination under saltstress can be effectively improved by directional phenotypic selection and that selection can be based on individual seed performance in early segregating generations.

Selections for improved germination were equally effective at all three salt-stress levels, and at each stress level, selection resulted in progeny with improved germination at a wide range of salt concentrations. These results indicate that similar or identical genes contributed to rapid seed germination at different salt-stress levels. Significant genotypic and genetic correlations between germination responses at different salt-stress levels further support this suggestion. The results are consistent with our previous findings that in an $\mathrm{F}_{2}$ population of an interspecific cross between a salt-tolerant accession (LA716, L. pennellii) and a salt-sensitive tomato cultivar (UCT5) similar QTLs (quantitative trait loci) contributed to rapid seed germination under different salt-stress levels (Foolad and Jones, 1993). The combined results suggest that to develop tomato cultivars with improved seed germination at diverse salt-stress levels, it is sufficient to conduct selection and breeding at a single salt-stress level.

PI174263 germinated more rapidly than UCT5 under salt-stress and nonstress treatments, and selection for rapid germination under salt-stress improved progeny germination under stress and nonstress treatments, indicating that similar genes contributed to rapid germination under both conditions. However, 1) relative differences between the two parents were larger in the presence rather than in the absence of salt (Table 1);2) unselected $\mathrm{F}_{2}, \mathrm{~F}_{3}$, and $\mathrm{F}_{4}$ populations germinated similar to UCT5 under nonstress treatment but germinated intermediate between the two parents under salt-stress treatments (Table 1);3) broad sense heritabilities were larger under stress than nonstress treatments (Tables 2 and 4); 4) genetic gains were generally larger in the presence rather than in the absence of salt; and 5) genotypic correlations were larger
Table 6. Phenotypic correlations between the time to $25 \%, 50 \%$, and $75 \%$ germination quantiles for tomato seed at four salt-stress levels. ${ }^{\mathrm{z}, \mathrm{y}}$

\begin{tabular}{lccc}
\hline \hline $\begin{array}{l}\text { Germination } \\
\text { quantile }\end{array}$ & $\begin{array}{c}\text { Salt } \\
\text { level }(\mathrm{mM})\end{array}$ & \multicolumn{2}{c}{ Germination quantile } \\
\cline { 3 - 4 } & 0 & 0.97 & $75 \%$ \\
& 100 & 0.95 & 0.85 \\
& 150 & 0.96 & 0.85 \\
$50 \%$ & 200 & 0.86 & 0.86 \\
& 0 & & $\mathrm{NA}^{\mathrm{x}}$ \\
& 100 & & 0.90 \\
& 150 & & 0.92 \\
& 200 & & 0.92 \\
& & & $\mathrm{NA}^{\mathrm{x}}$
\end{tabular}

${ }^{\mathrm{z}}$ Seed were germinated in darkness on media in petri dishes at $20 \pm 0.5^{\circ} \mathrm{C}$. yAll correlation coefficients were significant at $P \leq 0.01$.

${ }^{x}$ Not available; at the 200-mm salt concentration, most genotypes did not reach $75 \%$ germination by the end of experiments $(60 \mathrm{~d})$.

between germination under the various salt-stress treatments (i.e., 100,150 , and $200 \mathrm{~mm}$ salt) than between germination under stress and nonstress treatments (Table 5), indicating the presence of additional genes that are expressed only under salt stress. In our study, no distinction could be made between genes that generally contributed to rapid germination and genes that might be specific to salt tolerance. Selection experiments under nonstress treatment could be needed to resolve this situation. However, selection for rapid germination under salt-stress did not have apparent undesirable effects on germination in the absence of stress, suggesting that general improvement of tomato seed germination could be made by selecting under salt-stress treatment. This finding is particularly significant because germination variance is often much larger under stress than nonstress treatments (Table 2; also see Foolad and Jones, 1991) and, thus, selection might be more effective under stress treatment. It appeared that greater germination variances under stress rather than nonstress treatments were not completely due to genetic causes. For example, germination variances of parental lines also were greater under stress than nonstress treatment and increased with increasing stress intensity (Table 2). Greater germination variance under stress treatment is due partly to slower germination and, thus, longer time intervals between germination events. However, under salt-stress treatments, germination variances increased more in segregating than in nonsegregating populations, and broad sense heritabilities were larger under stress than nonstress treatments, suggesting contribution of some genetic factors to the larger variance under the stress treatment. Greater genetic variances in stress environments is one of the more favorable situations for plant breeders (Rosielle and Hamblin, 1981), although it does not appear to be a common occurrence (Daday et al., 1973; Johnson and Frey, 1967).

When measuring germination response time, earlier germination quantiles, such as T25, may have the advantage of being a quick way of measuring germination, whereas later germination quantiles, such as T50 and T75, may yield better estimates of a population germination performance and distribution. Correlation analysis indicated highly significant correlations between the various germination quantiles at all treatment levels (Table 6), which suggests that for response time traits like germination, earlier quantiles may be good predictors of family performance and, therefore, may provide greater economy in data acquisition and analysis. However, the correlation coefficients between T25 and T75 were smaller than those observed between T50 and T75 (Table 6). The T50 was highly correlated with the T25 and T75. In addition, in a previous study, larger narrow sense heritability was 
obtained for seed germination estimated based on T50 rather than that based on T25 or T75 (Foolad and Jones, 1992a). Therefore, T50 may be a better measure of germination performance when evaluating a population or selecting for improved germination.

The results of our study clearly indicated that for these tomato genetic materials, seed germination under salt stress was genetically controlled with additivity being the major genetic component. Significantly large genetic correlations between germination responses at different salt-stress levels indicate that similar or identical genes contributed to germination response under different salt-stress levels. Thus, selection for rapid germination at one stress level would result in progeny with improved germination at diverse salt-stress levels. Furthermore, significant positive relationships between germination under salt-stress and nonstress treatments indicate that genetic and physiological characteristics that facilitate rapid germination under salt-stress also might contribute to improved germination under nonstress conditions. Finally, seeds that germinate rapidly are expected to result in better emergence and stand establishment than seeds with greater dispersion of germination events over time.

\section{Literature Cited}

Ayers, A.D. and H.E. Hayward. 1948. A method for measuring the effects of soil salinity on seed germination with observation on several crop plants. Soil Sci. Soc. Amer. Proc. 13:224-226.

Bliss, R.D., K.A. Platt-Aloia, and W.W. Thomson. 1986. Osmotic sensitivity in relation to salt sensitivity in germinating barley seeds. Plant Cell and Environ. 9:721-725.

Bradford, K.J. 1990. A water relations analysis of seed germination rates. Plant Physiol. 94:840-849.

Bradford, K.J. 1995. Water relations in seed germination, p. 351-396. In: J. Kigel and G. Galili (eds). Seed development and germination. Marcel Dkker, New York.

Casler, M.D. 1982. Genotype $\times$ environment interaction bias to offspringparent regression heritability estimates. Crop Sci. 22:540-542.

Cook, R.E. 1979. Patterns of juvenile morbidity and recruitment in plants, p. 207-301. In: O.T. Solbrig, S. Jain, G.B. Johnson, and P.H. Raven (eds.). Topics in plant population biology. Columbia Univ. Press, Los Angeles.

Daday, H., F.E. Binet, A. Grassia, and J.W. Peak. 1973. The effect of environment on heritability and predicted selection response in Medicago sativa. Heredity 31:293-308.

Epstein. E, J.D. Morlyn, D.W. Rush, R.W. Kingsbury, D.B. Kelly, G.A. Cunningham, and A.F. Wrona. 1980. Saline culture of crops: A genetic approach. Science 210:399-404.

Falconer, D.S. 1981. Introduction to quantitative genetics. Longman, New York.

Flowers, T.J., M.A. Hajibagheri, and N.C.W. Clipson. 1986. Halophytes. Quart. Rev. Biol. 61: 313-337.

Foolad M.R. 1996. Genetic analysis of salt tolerance during vegetative growth in tomato, Lycopersicon esculentum Mill. Plant Breeding. (In press.)

Foolad, M.R. and R.A. Jones. 1991. Genetic analysis of salt tolerance during germination in Lycopersicon. Theor. Appl. Genet. 81:321-326.

Foolad, M.R. and R.A. Jones. 1992a. Parent-offspring regression estimates of heritability for salt tolerance during germination in tomato. Crop Sci. 32: 439-442.

Foolad, M.R. and R.A. Jones. 1992b. Models to estimate maternally controlled genetic variation in quantitative seed characters. Theor. Appl. Genet. 83: 360-366.
Foolad, M.R. and R.A. Jones. 1993. Mapping salt-tolerance genes in tomato (Lycopersicon esculentum) using trait-based marker analysis. Theor. Appl. Genet. 87:184-192.

Frey, K.J. and T. Horner. 1957. Heritability in standard units. Agron. J. 49:59-62.

Gehan, E.A. 1969. Estimating survival functions from the life table. J. Chron. Dis. 21:629-644.

Ginkel, M.V. and A.L. Scharen, 1987. Generation means analysis and heritabilities of resistance to Septoria tritici in durum wheat. Phytopathology 77:1629-1633.

Gorham, J., R.G.W. Jones, and E. McDonnell. 1985. Some mechanisms of salt tolerance in crop plants. Plant and Soil 89:15-40.

Greenway, H. and R. Munns. 1980. Mechanism of salt tolerance in nonhalophytes. Annu. Rev. Plant Physiol. 31:149-190.

Haigh, A.H. and E.W.R. Barlow. 1987. Water relations of tomato seed germination. Austr. J. Plant Physiol 14:485-492.

Hanson, W.D. 1963. Heritability, p. 125-140. In: W.D. Hanson and H.F. Robinson (eds.). Statistical genetics and plant breeding. Publ 982 Natl. Acad. Sci.-Natl. Res. Council, Washington, D.C.

Johnson, D.W., S.E. Smith, and A.K. Dobrenz. 1992. Genetic and phenotypic relationships in response to $\mathrm{NaCl}$ at different developmental stages in alfalfa. Theor. Appl. Genet. 83:833-838.

Johnson, G.R. and K.J. Frey. 1967. Heritabilities of quantitative attributes of oats (Avena $s p$ ) at varying levels of environmental stress. Crop Sci. 7:43-46.

Jones, R.A. 1986. High salt tolerance potential in Lycopersicon species during germination. Euphytica 35:575-582.

Jones, R.A. and C.O. Qualset. 1984. Breeding crops for environmental stress tolerance, p. 305-340. In: G.B. Collins and J.F. Petolino (eds.). Application of Genetic engineering to crop improvement. Nijihoff/Junk Publishers, Holland.

Lauchli, A. and E. Epstein. 1990. Plant responses to saline and sodic conditions, p. 113-137. In: K.K. Tanji (ed.). Agricultural salinity assessment and management. ASCE Press, New York.

Lee, E. 1980. Statistical methods for survival data analysis. Wadworth, Lifetime Learning Publ, Belmont, Calif.

Maas, E.V. 1986. Salt tolerance of plants. Appl. Agr. Res. 1:12-26.

Mather, K. and J.L. Jinks. 1971. Biometrical genetics. 2nd ed. Chapman and Hall, London.

Richards, R.A. 1983. Should selection for yield in saline regions be made on saline or non-saline soils? Euphytica 32:431-438.

Rosielle, A.A. and J. Hamblin. 1981. Theoretical aspects of selection for yield in stress and non-stress environments. Crop Sci 21:943-946.

Rush, D.W. and E. Epstein. 1976. Genotypic responses to salinity: differences between salt-sensitive and salt-tolerant genotypes of the tomato. Plant Physiol. 57:162-166.

Scott, S.J. and R.A. Jones. 1982. Low temperature seed germination of Lycopersicon species evaluated by survival analysis. Euphytica 31:869883.

Shannon, M.C. 1985. Principles and strategies in breeding for higher salt tolerance. Plant and Soil 89:227-241.

Steel, R.G.D. and J.H. Torrie. 1980. Principles and procedures of statictics. 2nd ed. McGraw-Hill, New York.

Tal, M. 1985. Genetics of salt tolerance in higher plants: theoretical and practical considerations. Plant and Soil 89:199-226.

Tal, M. and M.C. Shannon. 1983. Salt tolerance in the wild relatives of the cultivated tomato: responses of Lyconpersicon esculentum, L. cheesmanii, L. peruvianum, Solanum pennellii and $\mathrm{F}_{1}$ hybrids to high salinity. Austr. J. Plant Physiol. 10:109-117.

Vogel, K.P., F.A. Haskins, and H.J. Gorz. 1980. Parent-progeny regression in indiangrass: Inflation of heritabililty estimates by environmental covariances. Crop Sci. 20:580-582. 